\title{
Autonomic neuropathy, QT interval lengthening, and unexpected deaths in male diabetic patients
}

\author{
D.J.Ewing ${ }^{1}$, O. Boland ${ }^{1}$, J.M.M. Neilson ${ }^{2}$, C. G. Cho ${ }^{1}$ and B. F. Clarke ${ }^{3}$ \\ University Departments of 1 Medicine, and ${ }^{2}$ Medical Physics and Bioengineering, and ${ }^{3}$ Department of Diabetes, Royal Infirmary, \\ Edinburgh, UK
}

\begin{abstract}
Summary. QT intervals were measured over RR intervals ranging from $500 \mathrm{~ms}$ to $1000 \mathrm{~ms}$ in 13 normal male subjects, 13 male diabetic subjects without and 13 with autonomic neuropathy. There was a close linear relationship between QT and RR in all subjects. The slope of the regression line was significantly greater in the autonomic neuropathy group than the normal group. Thirty-two male diabetic subjects with varying degrees of autonomic dysfunction had repeat QT measurements 3 (range 2-6) years later. QT and QTC lengthened significantly at the second visit, unrelated to age or time between recordings, but which corresponded with changes in autonomic function. Of 71 male diabetic subjects
\end{abstract}

under 60 years followed for 3 years, 13 had died, 8 unexpectedly. Of those with autonomic neuropathy, QT and QTC were significantly longer in those who subsequently died, despite similar ages and duration of diabetes. We conclude that QT/RR interval relationships are altered in diabetic autonomic neuropathy, and that changes in QT length with time parallel changese in autonomic function. There may be an association between QT interval prolongation and the risk of dying unexpectedly in diabetic autonomic neuropathy.

Key words: Diabetes mellitus, autonomic neuropathy, QT interval, sudden death, autonomic function tests.
Diabetic subjects with clinical features of autonomic neuropathy may die suddenly and unexpectedly, but the mechanisms have not been elucidated [1]. There has been considerable recent interest in the relationship between QT interval length, diabetes mellitus and sudden death, with evidence to suggest that where diabetic autonomic neuropathy co-exists the QT interval is prolonged [2-6]. It has been speculated that this could provide a possible explanation for the unexpected deaths $[2,3,6]$, based on observations of the long QT syndrome and the sudden infant death syndrome [7]. To date, however, no firm evidence has been produced directly linking QT interval lengthening and sudden deaths in diabetic subjects.

This study was designed to try to throw further light on the possible mechanisms and the relationships between QT interval length and unexpected deaths by addressing three related questions. Firstly, is there good evidence of altered QT interval in diabetic autonomic neuropathy? We have previously shown that in the steady state there are small alterations in QT length associated with autonomic impairment [4]. We wanted to see whether QT/RR interval relationships were also altered in this group. Secondly, does QT interval lengthen with time during the progress of diabetes, and if so is this related to worsening autonomic function? Thirdly, was there a longer QT interval in those diabetic patients who had subsequently died, some suddenly and unexpectedly, when compared with those diabetic subjects who survived?

\section{Patients and methods}

\section{Patients}

We studied different groups in the three parts of the study. By their very nature the studies were retrospective as the QT measurements were taken from $24 \mathrm{~h}$ ECG tapes that had been recorded some time previously to examine heart rate variability. As, too, mostly male diabetic subjects had been included in these earlier studies, we confined our QT analyses to male subjects only.

$Q T / R R$ interval relationships. Three age-matched groups were studied: 13 normal subjects mean age 42 (range 28-60) years, 13 diabetic patients with normal cardiovascular reflexes (DAN-ve) mean age 41 (range 28-59) years, and 13 diabetic patients with abnormal cardiovascular reflexes (DAN + ve) mean age 42 (range $27-60$ ) years. All subjects had a previous ambulatory $24 \mathrm{~h} \mathrm{ECG}$ tape recording with good quality signals for analysis and a sufficiently wide range of heart rates (see methods section). At the time of their $24 \mathrm{~h}$ ECG tape all diabetic subjects had a standard battery of cardiovascular autonomic function tests, as we have described in detail previously [8]. Those who had normal tests and ANS scores of $0-2$ were 
classed as DAN - ve, while those who had definite or severe autonomic damage and ANS scores of 5-10 were classed as DAN + ve, as we have defined previously [8].

Repeat $Q T$ interval measurements. We selected only those male diabetic subjects who had two $24 \mathrm{~h}$ ambulatory ECG tape recordings at least two years apart, of sufficiently good quality for analysis, and whose recordings included periods of heart rate around 80 beats per min (see methods section). Thirty-two diabetic patients were eventually selected, mean age 39 (range 20-58) years, with degrees of autonomic dysfunction varying from none to severe. All subjects had standard cardiovascular tests done at the time of each visit, except five in whom no tests were performed at their second tape visit. At their first visit 17 had normal tests, 3 early, 3 definite and 7 severe abnormalities and 2 atypical patterns (21 had ANS scores of $0-2$, 2 scored $3-5$, and 9 scored 6-10).

Survey of $Q T$ interval length and deaths. In this retrospective analysis we selected all male diabetic subjects aged under 60 years, whose follow-up extended at least three years if they survived and who previously had a good quality $24 \mathrm{~h}$ ECG tape recording with a period of heart rate around 80 beats per min, and concurrent cardiovascular autonomic function tests performed. Seventy-one diabetic patients met these criteria. Thirty-nine had normal cardiovascular reflex tests (DAN - ve), mean age $41(28-58)$ years, while the other 32 had definite or severe cardiovascular reflex abnormalities (DAN + ve), mean age 44 (27-59) years. Causes of death were ascertained, where possible, from hospital case records and general practitioner notes. Unexpected deaths were defined as deaths which occurred suddenly and unexpectedly and without any obvious cause.

\section{Methods}

QT intervals were measured from ECG strips taken from the previously recorded ambulatory $24 \mathrm{~h} \mathrm{ECG}$ tapes. The tapes were originally made to study heart rate variation, and the chest electrode sites were chosen to optimise the recorded ECG complex for QRS wave detection and morphology classification. For the present purposes, a distinct $T$ wave with a clearly defined termination also had to be present. Of potential recordings approximately $30 \%$ were excluded for a variety of technical reasons, including poor ECG signals with indistinct $\mathrm{T}$ waves, or no period of recording at the required heart rates. We have described in detail previously how the ECG strips were played out and the QT and RR intervals measured over the same five consecutive beats by two independent observers, whose results were then averaged [4]. A corrected QT (QTC) was calculated for each QT measurement, using the formula $\mathrm{QTC}=\mathrm{QT} / \sqrt{\mathrm{RR}}$.

For the QT/RR interval study we selected up to eight ECG strips for QT measurements in each individual, over a range of RR intervals from 500 to $1000 \mathrm{~ms}$, equivalent to heart rates of approximately $60,65,70,80,90,100,110$ and 120 beats per min. Twelve normal, 9 DAN - ve and 3 DAN + ve subjects had a complete set of measurements; 1 normal, 3 DAN - ve and 4 DAN + ve subjects missed one of the two extreme heart rates; 5 DAN + ve subjects missed two measurements at the lower end of the heart rate range and 1 DAN - ve subject at the upper end.

For the follow-up study and deaths survey, only one ECG strip was required at around 80 beats per min (RR interval $750 \mathrm{~ms}$ ) for each $24 \mathrm{~h}$ recording. Although the QT interval results of the patients whose ECG strips we looked at in the deaths survey have previously been reported by us when we sought to determine whether QT interval was lengthened in diabetic autonomic neuropathy [4], the present results were arrived at independently. All the ECG strips were re-measured by two different observers, who were unaware of the previous results and outcome of the subjects, and who measured all traces in this present study. Total $24 \mathrm{~h}$ RR counts were also measured from the $24 \mathrm{~b}$ ECG tapes. This is a sensitive index of cardiac parasympathetic function [9].

\section{Statistical analysis}

Statistical analysis of the results was performed using the Minitab software programme (Minitab, State College, Pa., USA). In the QT/RR interval study a linear regression between RR interval and QT length was calculated for each individual and the slope of the regression line used in further calculations to determine differences between groups using a one-way analysis of variance technique followed by an unpaired $t$-test. The results from the other two studies were assessed using paired and unpaired $t$-tests within and between groups, and linear regression analysis, as appropriate. Results are presented as arithmetic mean $\pm \mathrm{SD}$, or geometric mean and range (log total 24 h RR counts).

\section{Results}

\section{QT/RR interval relationships}

There was a very close linear relationship between $R R$ interval and QT length in all subjects $(r=>0.9)$. Although the individual regression line slopes were widely scattered, the group mean value for the DAN + ve group was significantly greater than the value of the normal group $(0.243 \pm 0.04$ vs $0.205 \pm 0.03, p=0.017)$. The mean value for the DAN - ve group $(0.212 \pm 0.05)$ was intermediate and not significantly different from the values in the other two groups.

\section{Repeat $Q T$ interval measurements}

There was a median time between recordings of 3 (range 2-6) years. Table 1 shows the changes in QT length, QTC, ANS scores and log total $24 \mathrm{~h}$ counts with time in the 32 diabetic patients selected. QT and QTC measurements were significantly longer at the repeat visit, while the mean RR interval at which QT was measured remained unchanged. Although ANS scores increased (indicating worsening autonomic function), there was a wide scatter and the increase was not significant; whereas log $24 \mathrm{~h}$ RR counts decreased, with a marginal level of significance.

There was no relationship between age and QT interval $(r=0.07)$ or QTC $(r=0.05)$, or between age and changes in QT interval $(r=0.11)$ or QTC $(r=0.12)$. The lengthening of QT interval and QTC did not appear to be a function of the time between the two recordings, as there

Table 1. Group mean QT and RR intervals, ANS scores and $24 \mathrm{~h}$ $R R$ counts in 32 diabetic subjects whose measurements were repeated 2-6 years later (arithmetic mean $\pm \mathrm{SD}$, or geometric mean and range)

\begin{tabular}{llll}
\hline & Visit 1 & Visit 2 & Significance $(p)$ \\
\hline QT (ms) & $366 \pm 20$ & $375 \pm 24$ & 0.039 \\
QTC (ms) & $424 \pm 23$ & $435 \pm 27$ & 0.022 \\
RR (ms) & $745 \pm 15$ & $742 \pm 9$ & $0.31(\mathrm{NS})$ \\
$\begin{array}{l}\text { ANS score } \\
(n=27)\end{array}$ & & & \\
24 h RR counts & $8.9 \pm 3.5$ & $3.8 \pm 3.5$ & $0.11(\mathrm{NS})$ \\
$(n=30)$ & $(19-11251)$ & $(6-9484)$ & 0.051 \\
\hline
\end{tabular}


was no relationship between the time between the recordings and changes in QT interval $(r=0.07)$ or QTC $(r=0.09)$.

\section{Survey of $Q T$ interval length and deaths}

Of the 71 diabetic subjects followed-up, 13 (3 of $39 \mathrm{DAN}$ - ve and 10 of $32 \mathrm{DAN}+\mathrm{ve}$ ) had died within three years of the recording, 8 unexpectedly (1 DAN - ve, $7 \mathrm{DAN}+\mathrm{ve}$ ), 2 from unrelated causes (both DAN - ve), and 3 unknown (all DAN + ve). Within the overall group QT interval and QTC were significantly longer in those who had died (QT alive $363 \pm 17 \mathrm{~ms},(n=58)$, dead $387 \pm 33 \mathrm{~ms},(n=13), p<0.001$; QTC alive $420 \pm 20 \mathrm{~ms}$, dead $447 \pm 35 \mathrm{~ms}, p<0.001$ ). The RR intervals at which QT length was measured were not significantly different between the alive and dead groups (alive $748 \pm 18 \mathrm{~ms}$, dead $749 \pm 18 \mathrm{~ms}$, NS). Table 2 gives the analysis of the 32 DAN + ve subjects, with significantly longer QT intervals and QTC in the group who had died, but similar ages and duration of diabetes.

\section{Discussion}

Our results provide further evidence of altered QT/RR interval relationships in diabetic autonomic neuropathy. In addition they show that changes in QT interval length with time parallel changes in autonomic function; and that diabetic subjects with autonomic neuropathy who subsequently die have longer QT intervals than those who survive.

In a previous study we showed a small, but significant, lengthening of QT interval in the steady state, which we attributed to autonomic damage rather than diabetes per se [4]. In this current study QT intervals were measured over a wide range of RR intervals to see whether QT/RR interval relationships were disturbed in any way. We have confirmed that there is a close linear relationship between the two variables, and that the slope of the regression line was steepest in those with autonomic involvement (DAN + ve group). The results indicate that QT interval was longer in DAN + ve subjects, particularly at low heart rates. QT interval length is usually regarded as an indicator of the rate of myocardial repolarisation, and is depend-

Table 2. Mean QT interval and QTC values in diabetic subjects with autonomic neuropathy, grouped according to whether they were alive $(n=22)$ or dead $(n=10)$ three years later (mean \pm SD or range)

\begin{tabular}{lcccll}
\hline & $\begin{array}{l}\text { Age } \\
\text { (years) }\end{array}$ & $\begin{array}{l}\text { Duration } \\
\text { of diabetes } \\
\text { (years) }\end{array}$ & $\begin{array}{l}\text { QT } \\
(\mathrm{ms})\end{array}$ & $\begin{array}{l}\text { QTC } \\
(\mathrm{ms})\end{array}$ & $\begin{array}{l}\text { RR } \\
(\mathrm{ms})\end{array}$ \\
\hline $\begin{array}{l}\text { Alive } \\
(n=22)\end{array}$ & 42 & 13 & $364 \pm 17$ & $422 \pm 20$ & $742 \pm 16$ \\
$\begin{array}{l}\text { Dead } \\
(n=10)\end{array}$ & $\begin{array}{c}46 \\
(29-59)\end{array}$ & $\begin{array}{c}(2-29) \\
(2-31)\end{array}$ & $391 \pm 35$ & $452 \pm 37$ & $749 \pm 20$ \\
$\begin{array}{l}\text { Significance } \\
(p)\end{array}$ & $\mathrm{NS}$ & $\mathrm{NS}$ & $<0.01$ & $<0.01$ & NS \\
\hline
\end{tabular}

ent on autonomic, particularly sympathetic, control. Our QT/RR interval results would, therefore, confirm, albeit in a rather different way, the previous suggestions of $a b-$ normalities of QT interval length in diabetic autonomic neuropathy.

The argument that QT interval prolongation might have significant clinical consequences was originally proposed in relation to the congenital 'long QT syndrome' where death sometimes occurs suddenly in these subjects. It has been postulated that there is underactivity of the right stellate ganglion, with reflex compensatory overactivity of the left stellate ganglion, leading to QT prolongation and increased electrical instability of the myocardium which, in turn, may lead to sustained ventricular arrhythmias [7]. A similar argument has been put forward to explain some of the deaths associated with the sudden infant death syndrome', with uneven development of the right and left sided sympathetic supply to the heart in the first six months of life, leading to a similar electrical instability with potentially fatal arrhythmias [7]. In diabetes, where sudden and unexpected deaths also occur, a similar mechanism has been proposed $[2,3,6]$. However, although QT interval prolongation has been reported by several groups [2-6], including our own [4], no group has yet produced anything more than tentative suggestions linking prolonged QT intervals and sudden death in these patients. Neither has there been any convincing explanation put forward of the possible mechanisms that might give rise to QT prolongation in individuals with diabetes.

Although we are still unable to do more than speculate about these mechanisms, our study now provides the first real link between QT interval length and subsequent unexpected death in diabetic autonomic neuropathy. It should, of course, be recognised firstly that association does not imply causation; and secondly that these observations are retrospective in nature, and therefore have to be interpreted with some caution. We have attempted to minimise bias by confining our study to those who had good quality ECG records, and selecting them on this basis, rather than by their autonomic neuropathy status. We used an arbitrary cut-off point of three years, as we felt that beyond this time the previous $24 \mathrm{~h}$ tape became of less relevance as new factors and circumstances emerged. When those with abnormal autonomic function were analysed, there were significant differences in QT interval length between those who had died and those who survived, which we feel may be related to their survival, possibly by a mechanism of increased electrical instability and the potential for ventricular arrhythmias. How exactly QT lengthens is not clear; it may be that the autonomic nerves controlling myocardial repolarisation are damaged therefore slowing this process. Kahn and colleagues showed one diabetic patient with diffuse adrenergic myocardial loss, who also had a prolonged QT interval [2].

It has been suggested that QT interval lengthening may be due to technical factors unrelated to autonomic neuropathy. QT interval length on the electrocardiogram varies, according to which lead is chosen [10], and it is theoretically possible that all those who died were recorded on the 'longest' lead, while those who survived on the 'shortest' lead. We feel this is unlikely as there is only a 
relatively norrow choice of chest lead positions for $24 \mathrm{~h}$ ECG taping, with no limb leads used. Indeed, anteroseptal chest leads probably give the closest approximation to the maximum QT length [10]. Also, if some subjects were recorded on the 'longer' leads, this is more likely to be scattered throughout the sample, rather than confined to just one sub-group. Could the QT lengthening be explained by myocardial, rather than autonomic damage? There is conflicting evidence on the relationship of QT length and prognosis after myocardial infarction [11]. QT interval lengthening is not a usual feature of most other clearly defined cardiac conditions.

Further supportive evidence for our hypothesis that QT interval lengthening is associated with autonomic neuropathy comes from the results of our follow-up study. Although the same criticisms about the follow-up study being retrospective are, of course, valid; nevertheless a fair spread of autonomic abnormality was achieved among the diabetic patients selected, and QT interval lengthening seemed to parallel the deterioration in autonomic function, as determined by standard cardiovascular reflexes and $24 \mathrm{~h}$ counts. We had previously shown no relationship between either QT or QTC and age in normal subjects [4]. Very recently a prospective follow-up study has been briefly reported, in which QTC measurements were found to lengthen over 5 years in diabetic subjects but remained the same in normal subjects [12].

This study has, therefore, shown that in diabetes QT interval, which is dependent on autonomic control, may be prolonged and could lead to conditions of increased myocardial electrical instability. This, in turn, might predispose diabetic subjects with autonomic neuropathy to potentially fatal ventricular arrhythmias, and provide a further possible explanation for the sudden and unexpected deaths that occur. We would, therefore, conclude that, from the evidence we have presented, there may be an association between QT interval prolongation and the risk of dying unexpectedly in diabetic subjects with autonomic neuropathy.

Acknowledgements. We thank Dr. R. J.Prescott, Medical Statistics Unit, University of Edinburgh for his help with the statistical analysis. The study was supported by grants from the Chest, Heart and Stroke Association (Scotland) and the Wellcome Trust.

\section{References}

1. Ewing DJ, Clarke BF (1986) Autonomic neuropathy: its diagnosis and prognosis. Clin Endocrinol Metab 15: 855-888

2. Kahn JK, Sisson JC, Vinik AI (1987) QT interval prolongation and sudden cardiac death in diabetic autonomic neuropathy. $\mathrm{J}$ Clin Endocrinol Metab 64: 751-754

3. Bellavere F, Ferri M, Guarini L, Bax G, Piccoli A, Cardone C, Fedele D (1988) Prolonged QT period in diabetic autonomic neuropathy: a possible role in sudden cardiac death? Br Heart J 59:379-383

4. Ewing DJ, Neilson JMM (1990) QT interval length and diabetic autonomic neuropathy. Diabetic Med 7: 23-26

5. Gonin JM, Kadrofske MM, Schmaltz S, Bastyr EJ, Vinik AI (1990) Corrected Q-T interval prolongation as diagnostic tool for assessment of cardiac autonomic neuropathy in diabetes mellitus. Diabetes Care 13: 68-71

6. Chambers JB, Sampson MJ, Sprigings DC, Jackson G (1990) QT prolongation on the electrocardiogram in diabetic autonomic neuropathy. Diabetic Med 7: 105-110

7. Schwartz PJ (1984) Sympathetic imbalance and cardiac arrhythmias. In: Randall WC (ed) Nervous control of cardiovascular function. Oxford University Press, New York Oxford, pp 225252

8. Ewing DJ, Martyn CN, Young RJ, Clarke BF (1985) The value of cardiovascular autonomic function tests: 10 years experience in diabetes. Diabetes Care 8: 491-498

9. Ewing DJ, Neilson JMM, Travis P (1984) New method for assessing cardiac parasympathetic activity using 24 hour electrocardiograms. Br Heart J 52: 396-402

10. Cowan JC, Yusoff K, Moore M, Amos PA, Gold A, Bourke JP, Transuphaswadikul S, Campbell RWF (1988) Importance of lead selection in QT interval measurements. Am J Cardiol 61: 83-87

11. Ward DE (1988) Prolongation of the QT interval as an indicator of risk of a cardiac event. Eur Heart J 9 [Suppl G]: 139-144

12. Jermendy G, Toth L, Voros P, Koltai MZ, Pogatsa G (1990) QT interval in diabetic autonomic neuropathy. Diabetic Med 7: 750

Received: 9 July 1990

and in revised form: 9 October 1990

Dr. D.J. Ewing

Department of Medicine

Royal Infirmary

Edinburgh EH3 9YW

UK 